\title{
Delayed Diagnosis of a Pyloric Web Causing Gastric Outlet Obstruction in a 13-Month-Old Girl
}

\author{
Mohammed Elifranji $^{1,2}$ jisha Sankar ${ }^{3} \quad$ Israa Abdelrasool $^{3}$ Guy Brisseau ${ }^{4}$
}

${ }^{1}$ Department of Surgery, Sidra Medicine, Doha, Qatar

${ }^{2}$ Department of Pediatric Surgery, Hamad Medical Corporation, Doha, Qatar

${ }^{3}$ Department of Gastroenterology, Sidra Medicine, Doha, Qatar

${ }^{4}$ Department of Pediatric Surgery, Sidra Medicine, Doha, Qatar

Eur J Pediatr Surg Rep 2021;9:e20-e22.
Address for correspondence Mohammed Elifranji, MD, MRCSI, FEBPS, Department of Surgery, Sidra Medicine, Al Gharrafa Street, Ar-Rayyan, Doha, Qatar (e-mail: mifranji@live.com).
Abstract
Keywords
- gastric outlet obstruction
- pyloric web
- atresia

Pyloric web is a rare cause of gastric outlet obstruction. Classical pyloric web can be diagnosed by obtaining a patient history, physical examination, and plain abdominal X-ray, whereas a perforated web leads to incomplete intestinal obstruction. Delayed diagnosis is rare, and the definite diagnosis is made by upper endoscopy. In this report, we report a case of a girl in whom a pyloric web was diagnosed at the age of 13 months.

\section{New Insights and the Importance for the Pediatric Surgeon}

Pyloric web is a rare entity of gastric outlet obstruction and can present with nonspecific symptoms that can cause a delay in diagnosis.

Thus, a high index of suspicion in addition to an upper gastrointestinal endoscopy can help achieve a definite diagnosis. Surgical intervention remains the best modality of treatment.

\section{Introduction}

Gastric outlet obstruction can be caused by prepyloric or pyloric abnormalities. Most of the cases reported in the literature refer to the gastric antral web as a cause of gastric outlet obstruction. ${ }^{1}$ Pyloric web, the most common type of pyloric atresia (PA), is diagnosed during the neonatal period with nonbilious vomiting. Its delayed detection is very rare. ${ }^{2}$ Hence, only a few cases report on pyloric web as a cause of gastric outlet obstruction in infancy. ${ }^{1}$ We report a case of an infant with a delayed diagnosis of pyloric web, as well as the challenges in the diagnosis and management.

\section{Case Report}

The patient was a 13-month-old girl who was born full term with a birth weight of $3.1 \mathrm{~kg}$. Her symptoms started with

received

August 3, 2020

accepted after revision

September 24, 2020
DOI https://doi.org/

10.1055/s-0041-1723017.

ISSN 2194-7619. nonbilious vomiting on the second day of life; however, her growth and weight were not affected. After 6 months of age, her symptoms progressed, and occasional coffee ground vomiting started in addition to a plateau in her weight. Therefore, different milk formulas were tried without much improvement of the vomiting. Her weight was on the third percentile, and the blood tests were negative for food allergens, Helicobacter pylori, and celiac disease, but positive for occult stool blood. The abdominal ultrasound showed a distended stomach and a normal-looking pylorus ( - Fig. 1A, B).

Consequently, upper gastrointestinal (UGI) contrast study showing delayed gastric emptying without anatomical filling defect ( - Fig. 2).

Therefore, the child was treated conservatively for delayed gastric emptying and symptomatic gastroesophageal reflux. However, she continued to vomit beyond a certain volume of food especially solid food. Thus, an

\section{(C) 2021. The Author(s).}

This is an open access article published by Thieme under the terms of the Creative Commons Attribution License, permitting unrestricted use, distribution, and reproduction so long as the original work is properly cited. (https://creativecommons.org/licenses/by/4.0/)

Georg Thieme Verlag KG, Rüdigerstraße 14, 70469 Stuttgart, Germany 

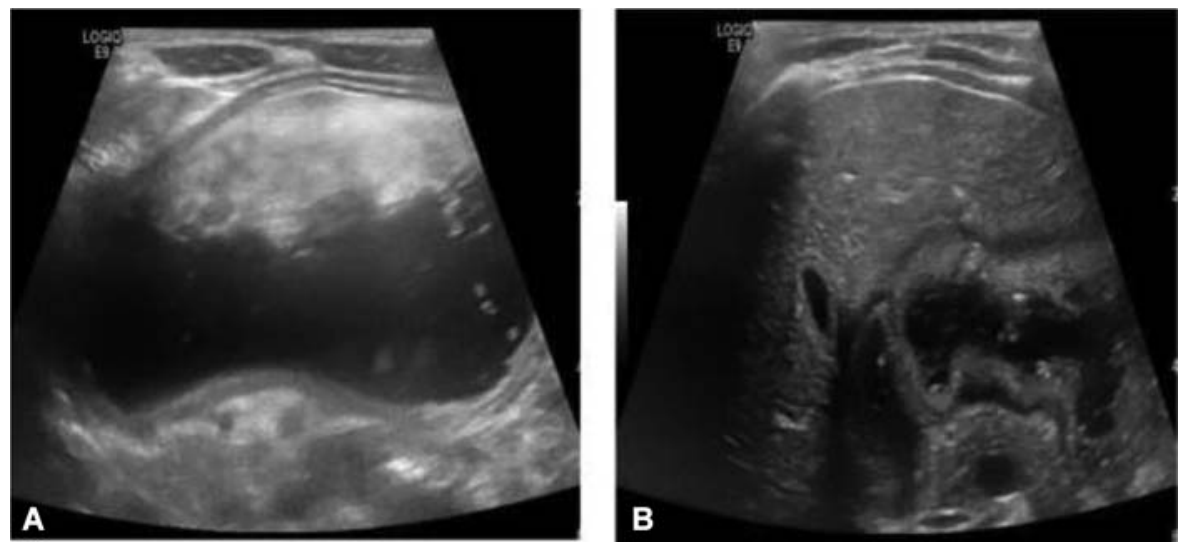

Fig. 1 Ultrasound of the abdomen showing a grossly distended stomach. (A) and normal pylorus without thickening (B).

esophagogastroduodenoscopy was performed, which showed a pyloric web with a pinhole opening in addition to a diffuse inflammation in the stomach and lower esophagus. Several attempts were made to cannulate the pylorus but with no success (-Fig. 3).

After a week adjustment of the malnourished state through parental nutrition through a peripherally inserted central catheter line, the patient was taken for operative exploration through a right upper quadrant transverse incision. The pylorus was delivered and looked thickened, and a full-thickness longitudinal incision on the anterior surface of the pylorus was made and a pyloric web was detected. A partial excision of the web was performed leaving the posterior wall of the pylorus intact followed by a Heineke-Mikulicz pyloroplasty. The patient was started on oral feeds after 48 hours with low volumes, which were gradually increased to achieve full oral feeding on postoperative day 5 .

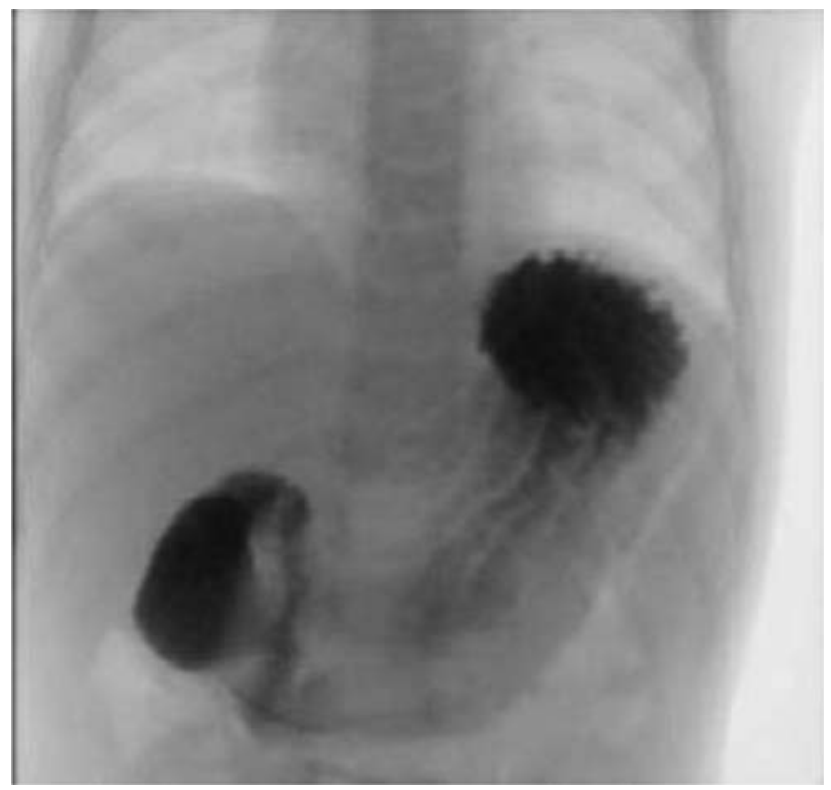

Fig. 2 Upper gastrointestinal contrast showing delayed passage of contrast from the stomach into the duodenum.

\section{Discussion}

Pyloric web is the most common type of PA, which in itself is a very rare pathology. ${ }^{2} \mathrm{PA}$ constitutes approximately $1 \%$ of all intestinal atresias, with an incidence of approximately 1 in 100,000 live births. ${ }^{3,4}$ Although the developing mechanism is not clear, some hypotheses suggested a susceptibility, genetic transition, recanalization, and vascular damage in the embryonic period. ${ }^{5,6}$ From an anatomy point of view, PA has been classified into three types: a pyloric membrane/web (type 1 : $57 \%$ ), a solid cord (Type 2: $34 \%$ ), or a gap between the stomach and duodenum (type 3: 9\%)., It can also be classified into isolated PA (35\%), PA associated with epidermolysis bullosa (40\%), and PA associated with other anomalies (25\%). ${ }^{8}$

Therefore, the presenting symptoms and time of diagnosis can vary between cases according to the degree of obstruction and associated comorbidities. Prenatal diagnosis may be possible in cases with a dilated stomach, absence of a double bubble sign, and presence of polyhydramnios, as reported in $50 \%$ of cases in the last trimester. However, the findings were

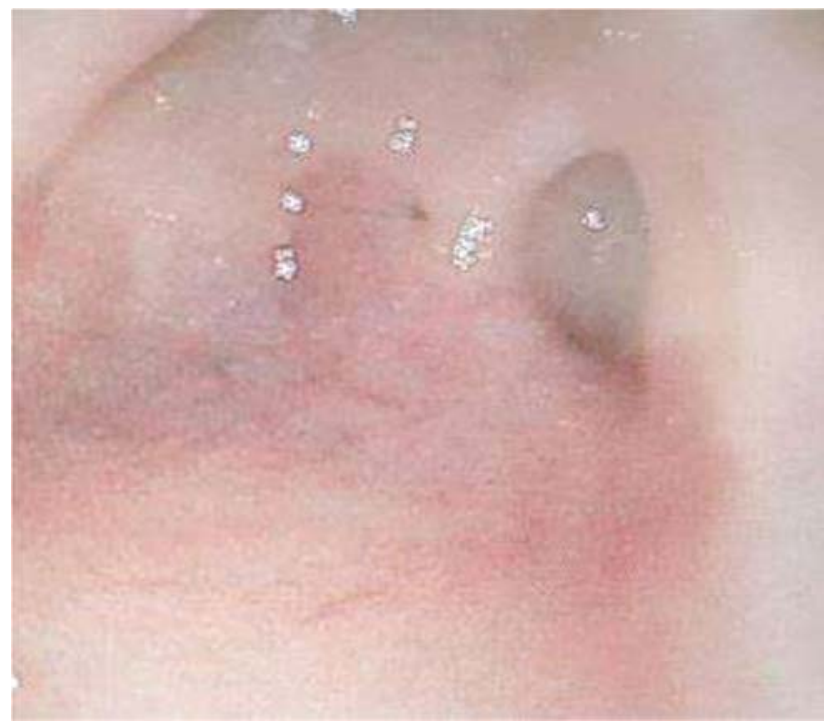

Fig. 3 Esophagogastroduodenoscopy showing a pyloric web with a tiny hole and inflammation in the stomach. 
not consistent due to the physiological variation in the fetal stomach size and infrequent appearance of polyhydramnios. ${ }^{9-11}$ On the other hand, the presentation after birth can vary from nonbilious vomiting, failure to thrive, and abdominal distension. Delayed presentation is possible and could be due to a partial obstruction causing a subtle course of the disease, as well as later presentation of the symptoms, absence of primary health care facilities, and possible ignorance of this rare entity, as reported in Kansra et al's study that showed the median age at the onset of symptoms was 6 months ( 1 day to 36 months) and the median age at presentation to the hospital was 7 months ( 1 day to 44 months) with a 5-month mean delay between them. ${ }^{12}$

The diagnosis of PA cases is straightforward and can be achieved through patient history, physical examination, and plain abdominal X-ray. An exception is a perforated web causing a partial intestinal obstruction. The diagnosis can be delayed, but radiological, ultrasonographic, and endoscopic investigations can be helpful. ${ }^{6}$ Even though it is challenging to make an accurate diagnosis, which can be delayed even with the use endoscopy or UGI series, such an entity is rare and cannot be easily managed by a clinician who has no previous knowledge about it. Such patients including our case have been treated for pyloric spasm with hyperacidity. ${ }^{13,14}$ Moreover, the partial improvement with the $\mathrm{H}_{2}$ blocker suggests that feeding intolerance with occasional coffee ground vomitus could be due to peptic ulcer disease in spite of being not common compared with older children. Hence, a high index of suspicion is required in patients presenting with nonbilious vomiting and failure to thrive as they may be wrongly diagnosed and treated for gastroesophageal reflux or peptic ulcer disease.

The treatment for PA is surgical and depends on the type of atresia. $7,15,16$ The recommended procedure for type 1 is an excision of the web and a Heineke-Mikulicz pyloroplasty and for type 2 is the excision of the pylorus with end-to-end gastroduodenostomy. However, Dessanti et $\mathrm{al}^{16}$ described a pyloric sphincter reconstruction: "gastroduodenal mucosal advancement anastomosis." For type 3, the treatment is gastroduodenostomy.

The endoscopic treatment is not clear for PA, but it may be considered for antral web when endoscopic intervention is feasible. If the mucosal structure of the antral web is uniform without major vessels or muscular or serosal layers and the membrane is tense and consistent with perpendicular insertion, then endoscopic transection is possible. ${ }^{17}$

In this study, our case had an isolated, incomplete type 1 atresia and therefore presented with subtle and nonspecific symptoms that waxed and waned over a period of time and made the diagnosis challenging. Although endoscopy was useful for making the diagnosis, it was not effective for treatment due to the failure to cannulate the pyloric web hole. Thus, surgical intervention was commenced, and a modified technique was performed to repair the pyloric web. The incision of the web was accomplished followed by a Heineke-Mikulicz pyloroplasty. Our patient had an uneventful postoperative course and went home on day 5 after tolerating oral feeding.
Furthermore, it is deemed that the excision of the web can cause avoidable complications, such as injury to major blood supply or nearby biliary drainage system, and achieve a similar outcome when simply incising it. However, further prospective studies are needed.

In conclusion, pyloric web is a rare entity of gastric outlet obstruction and can present with nonspecific symptoms that can cause a delay in diagnosis. Thus, a high index of suspicion in addition to an UGI endoscopy can help achieve a definite diagnosis. Moreover, surgical intervention remains the best treatment.

Conflict of Interest

None declared.

\section{References}

1 Otjen JP, Iyer RS, Phillips GS, Parisi MT. Usual and unusual causes of pediatric gastric outlet obstruction. Pediatr Radiol 2012;42 (06):728-737

2 Nawaz A, Matta H, Jacobsz A, Al-Salem A. Congenital pyloric atresia and junctional epidermolysis bullosa: a report of two cases. Pediatr Surg Int 2000;16(03):206-208

3 Ilce Z, Erdogan E, Kara C, et al. Pyloric atresia: 15-year review from a single institution. J Pediatr Surg 2003;38(11):1581-1584

4 Okoye BO, Parikh DH, Buick RG, Lander AD. Pyloric atresia: five new cases, a new association, and a review of the literature with guidelines. J Pediatr Surg 2000;35(08):1242-1245

5 Knouff S, Klein A, Kaminski M. Pyloric atresia in the neonate. Neonatal Netw 2014;33(06):329-335

6 Holcomb G, Murphy JP, Ostlie D, eds. Ashcraft's Pediatric Surgery. 5th ed. Philadelphia, PA: WB Saunders; 2010:408

7 Moore CCM. Congenital gastric outlet obstruction. J Pediatr Surg 1989;24(12):1241-1246

8 Al-Salem AH, Abdulla MR, Kothari MR, Naga MI. Congenital pyloric atresia, presentation, management, and outcome: a report of 20 cases. J Pediatr Surg 2014;49(07):1078-1082

9 Peled Y, Hod M, Friedman S, Mashiach R, Greenberg N, Ovadia J. Prenatal diagnosis of familial congenital pyloric atresia. Prenat Diagn 1992;12(02):151-154

10 Frisova V, Kavalcova L, Kyncl M, Vlk R, Kucera A, Rocek M. Congenital gastric outlet obstruction by pyloric membrane: prenatal and postnatal diagnosis and management. Fetal Diagn Ther 2009;26(02):98-101

11 Hasegawa T, Kubota A, Imura K, et al. Prenatal diagnosis of congenital pyloric atresia. J Clin Ultrasound 1993;21(04):278-281

12 Kansra M, Raman VS, Kishore K, Khanna S, Puri B, Sharma A. Congenital pyloric atresia - nine new cases: Single-center experience of the long-term follow-up and the lessons learnt over a decade. J Pediatr Surg 2018;53(11):2112-2116

13 Jung J, Moon KR. A case of an antral web with a gastric ulcer due to ibuprofen. Korean J Pediatric Gastroenterol Nutr 2010;13:66-69

14 Choi KJ. Prepyloric gastric antral webs in children-report of two cases and review of the literature. J Korean Surg Soc 1988; 35:610-614

15 Al-Salem AH. Congenital pyloric atresia and associated anomalies. Pediatr Surg Int 2007;23(06):559-563

16 Dessanti A, Di Benedetto V, Iannuccelli M, Balata A, Cossu Rocca P, Di Benedetto A. Pyloric atresia: a new operation to reconstruct the pyloric sphincter. J Pediatr Surg 2004;39(03):297-301

17 Berr F, Rienmueller R, Sauerbruch T. Successful endoscopic transection of a partially obstructing antral diaphragm. Gastroenterology 1985;89(05):1147-1151 